\title{
NEWS FROM ERIC
}

\author{
Submitted by \\ Nancy R. Preston
}

\section{ERIC Clearinghouse Competition}

Contracts were awarded in June for the operation of the 16 ERIC clearinghouses, ending a competetive process begun in November 1992. The five-year contracts all went to the groups previously operating the clearinghouses. Two clearinghouses moved to new universities, and several changed names as a result of the recompetition. New names include:

- $\quad$ Counseling and Student Services (was Counseling and Personnel Services);

- Disabilities and Gifted Education (was Handicapped and Gif ted Education);

- Community Colleges (was Junior Colleges)

- Reading, English, and Communication (was Reading and Communication Skills);

- Teaching and Teacher Education (was Teacher Education);

- $\quad$ Assessment and Evaluation (was Tests, Measurement, and Evaluation).

- Information \& Technology (was Information Resources).

The Counseling and Student Services clearinghouse moved from the University of Michigan to the University of North Carolina at Greensboro. The other clearinghouse to move was Assessment and Evaluation, which was sponsored by the American Institutes for Research and is now at Catholic University of America.

\section{New Contracts Bring Improvements}

Under the new ERIC contracts, all clearinghouses will establish toll-free telephone numbers for better access by the education community. Not all of the new 800 numbers are in place as of this writing. At any time, however, a current list of clearinghouses, with phone numbers, fax numbers, and Internet addresses, can be obtained from ACCESS ERIC, 1-800-LET-ERIC (538-3742).

Anothersystem improvement initiated with the new clearinghouse contracts is the processing of the best education-related books for the ERIC database. While it was previously possible for commercially published books to be entered into ERIC as documents (that is, announced in the Resources in Education index), the practice was limited because copyright holders were usually unwilling to allow any type of reproduction by the ERIC system.

Surveys of librarians and other users showed, however, that people want to see education-related books in ERIC, even though access to them cannot be guaranteed. So, as of mid-1993, users should begin to see a marked increase in the number of commer- cially published books indexed and abstracted in Resources in Education.

\section{ERIC Video Announced}

ERIC: In Action is a 15-minute video offering viewers a broad perspective on ERIC as their premier source for education information. Appropriate for students, librarians, and trainers, the video covers the basics of ERIC and provides an excellent lead- in to further discussion on the ERIC database, the subjectrelated clearinghouses, and ACCESS ERIC, the reference and referral arm. The video also highlights the Internet-based AskERIC service and the role of ERIC in national and intemational information networks.

The video was produced by the Clearinghouse on Information \& Technology, and can be ordered from either of these sources:

Information Resources Publications, ERIC/IT, 4-194 Center for Science and Technology, Syracuse University, Syracuse, NY $13244-4100$ (\$17, shipping included)

ACCESS ERIC, 1600ResearchBoulevard, Rockville MD 20850$3172,1-800-538-3742$ ( $\$ 17$, shipping included).

Nancy R. Preston is Assistant Director, ERIC Clearinghouse on Information \& Technology, 4-194 Center for Science and Technology, Syracuse University, Syracuse, NY 13244-4100; (315) 443-3640;800464-9107; npreston@erici.syr.edu. 